\title{
Slovaki (ja natuke läti) folkloristikast konverentsikülalise pilguga
}

\author{
Mare Kõiva
}

Enne Slovakkiasse sõitmist ei teadnud kumbki meist slovaki folkloristikast rohkem kui seda, et seal ilmub huvitavat erialakirjandust, mis viitab elavale teadustegevusele. Olin lugenud paari Gabriela Kiliánová artiklit ja Zuzana Profantova raamatut vanasõnadest. Teadsin, et Gabriela Kiliánová on juhtivaid Euroopa tegevfolkloriste, hõivatud mitmetest administratiivsetest kohustustest. Aga ei midagi enamat. Erinevatel, aga kindlasti ka keelest tulenevatel põhjustel pole eesti- ja slaavikeelse folkloristika vahel tihedaid sidemeid olnud. Selle tõttu oli mulle ja Andres Kuperjanovile võimalus võtta osa 23.-26. oktoobrini 2002 Bratislavas peetavast konverentsist teemal Traditional Culture as a Part of Cultural heritage of Europe. Presence and perspective of Folklore and Folkloristics vastupandamatu.

Euroopa folkloristika seisund erineb piirkonniti. Uue sajandi alguses on seniste meetodite ja tulemuste hindamine ning möödunud sajandi teoreetiliste otsingute summeerimine peaaegu et kohustuslik, igatahes aga vajalik. Tavaliselt tekib konverentside käigus häid ideid edasisteks uurimusteks ja ka teatav pingestav võrdlusmoment - kuhu asetub rahvuslik folkloristika, millisel tasemel ollakse, millised on võimalikud haakumispinnad erinevates piirkondade mentaalse kultuuri uuringutega. Nii sellelgi korral.

Konverentsi kohvipauside ajal arutleme, kuidas ja milliste meetoditega jälgitakse ja analüüsitakse traditsioonilist kultuuri, kuidas tuleks valgustada ühiskonnale olulisi teemasid, mis juhtub siis, kui traditsioonilised suunad hüljatakse ja sööstetakse moeteemade juurde, kas on võimalik hüpata üle sovetiaastatel vahele jäänud teoreetilise kirjanduse puudumisest ja meetodite lahknevusest jpm.

Oleme selle kõik õigupoolest sisse juhatanud teel Slovakkiasse, visiidi ajal Läti Rahvaluule Arhiivi, kuhu suundume neljaks tunniks, lennuki väljumiseni. Niisiis kohtume heade kolleegide Māra Vīksna, Guntis Pakalnsi ja Aldis Putelisega, kellega arutleme folkloristika käekäigu üle. Naabermaade Eesti ja Läti folkloristika on läinud algusest peale erinevat teed, kuid näiteks tänapäeva narratiivide uurimises on sarnast, folkloorist enesest kõnelemata. Läti folklo- 


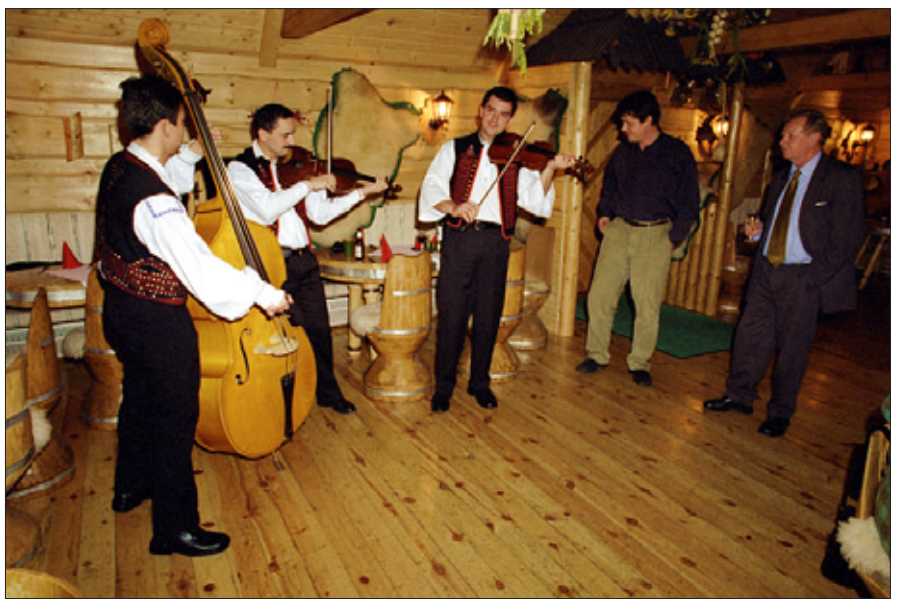

Foto 1. Slovaki rahvamuusikutega koos laulavad tantsu-uurija Ivan Murin ja Komenski ülikooli etnoloogia õppetooli juhataja Milan Leščak. Andres Kuperjanovi foto 2002.

ristidel on väga tugev meediaväljund raadio-ja TV-saadetena, samuti elav koostöö praktikutega ja praktilise suuna eestvedajatega. Paraku pole Lätis rahvaluule õppetooli olnud ega ole, mistõttu folkloristiks saadakse tugeva kutsumuse ja mitte järjepideva koolitusega. Erandiks on akadeemik Janina Kursīte algatatud semiootilise kallakuga läti mütoloogia kursused Läti Akadeemias. Kogu vestlusest vaba aja sirvime, loeme, lehitseme Läti arhiivis erialaseid raamatuid, sest kirjanduse kättesaadavusega on ikka veel nii nagu on. Klassikalise kirjandustegelase sõnutsi - nagu polegi teist õieti.

Bratislava üllatab kõigega esimesest hetkest viimaseni. Meie konverents peetakse äsja restaureeritud Palffy aiapalees, mille keldris taastatakse jätkuvalt seinakaunistusi. Kogu vanalinnas ja selle ümbruses keeb taastamis-, renoveerimis- ja uuehitustöö - otse aiapalee kõrvale kerkivad sellega kontrasteerivad moodsad elumajad. Palffy palee harmoneerub juudi restoraniga Gosher ja kunagise juudi linnajaoga, mida meenutab veel lähedalasuv juudi muuseum jm. Ülilähedal on Ungari kuningate kunagine kroonimiskirikja 1960. aastatel taastatud kindlus, mille alla suubub trammitee. Kuid konverentsikiirus ei jäta aega kummassegi sisenemiseks. Linnusemäele ja selle ümbruse kõrgendikele ronime mõnelgi öötunnil imetlema luksusvillasid ja vanalinna. Liigume palju jala ja 


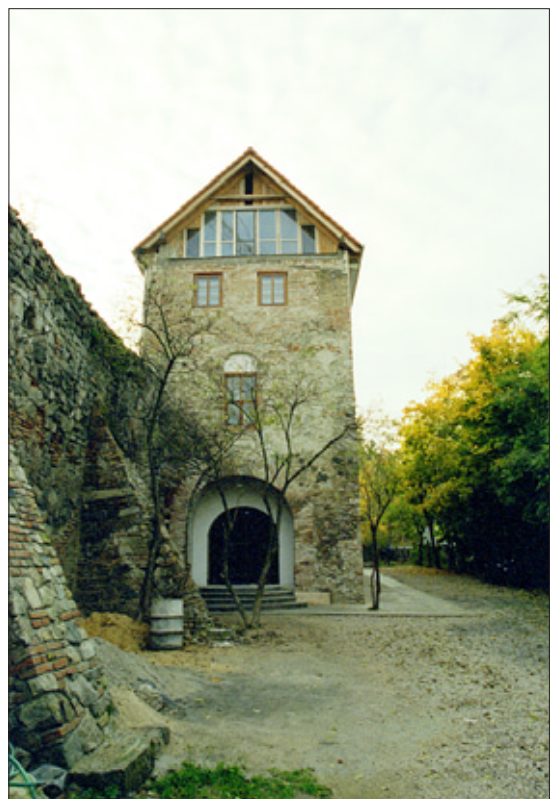

Foto 2. Konverents toimus äsja restaureeritud Palffy aiapalees, Bratislava ajaloolises vanalinnas. 2002. Andres Kuperjanovi foto. trammiga. Õigemini jääme igal ôhtul salapärasel kombel maha viimasest trammist ja alustame oma kuuekilomeetrist öömatka üliõpilaskülasse.

Satume linnas igat liiki ja masti kontrastidele ja seegi lisab konverentsile väärtust. Slovaki ja vene keele vahe näib olevat sama eksitav kui eesti ja soome keele oma - saab ju räägitud, kuid võib ka rumala jutu eest peksa saada.

Olen kummastunud sovetiaja kirjeldustest, võimu ja vaimu suhetest toonases Slovakkias. Kommunismihaare on siin olnud ilmselgelt tugevam kui Eestis: informaalsete võrgustike süsteem ja stratifikatsioonid, jälitamis- ja edutamissüsteemid, kommunistide eelised ühiskonnas. Juba reisi esimesse päeva jääb jahmatus noore daami semulikust repliigist, milles ta viitab informaalsele sovetlikule võrgustikule, mis olevat meil ja neil teadagi ühesugune ja töötav. Kuidagiviisi sugeneb see temaatika kergesti tänava-jm vestlustesse. Nii on Slovakkias taas kord võimalus kogeda sotsialismi ja postsotsialismi erinäolisust enam kui "kuuendikul kogu planeedist". Iseenesest paeluv teema enesevaatluseks ja uurimisekski.

Nihkudes pikapäevalise ja hästi korraldatud konverentsi juurde (peakorraldaja Zuzana Profantova), siis selle sektsioonides käsitleti folkloristika üldteoreetilisi küsimusi (V. Voigt, G. Kiliánová, Z. Profantova, B. Benes), erinevate rahvaluuleliikide uurimise võimalusi ja muutusi uurimisparadigmaatikas (W. Espelund, M. Leščák, R. Ivanova, E. Krekovicová). Vaadeldi rahvamuusika ja -tantsude uurimist, folkloristika ja folkloori seoseid digitaliseerimisega, tutvustati erinevate uurimissuundade, nagu semiootika ja antropoloogia, väljendumist folkloristikas, interdistsiplinaarseid uurimissuundi tänapäevases folkloristikas, ulmekirjanduse ja folkloristika kokkupuu- 
tealasid jm. Interneti-teemadest käsitleti näiteks linnamuistendeid ingliskeelses Interneti keskkonnas ja Ungari valimiseelse ja -aegse veebi poliitilisi nalju. Oli ka vanade, kuid taasaktualiseerunud teemade uusimatel küsitlustulemustel põhinevaid analüüse (inglid ja karistusmotiivid tänapäeva külaelanike uskumustikus), laste hirmujutud, esindatud oli mõistagi linnamuistendite teema.

Omaette rühma moodustasid ettekanded, mis käsitlesid folkloori ja folklorismi, folkloori õpetamist kõrgkoolist muude koolisüsteemideni, folkloori elu laval, poliitikas ja meedias, folklooritekstide avaldamisproblemaatikatjne.

Osavõtjad said hea ülevaate slovaki folkloristikast ja tutvusid tšehhi, bulgaaria, sloveenia, ungari, austria, eesti ja norra rahvaluule uurimise suundumustega.

Sügava mulje jättis konverentsi kultuuriprogramm - ooperiteatri külastus ja avatseremoonia hea klassikalise muusikaga, mis harmoneerus palee õhustikuga ja mille juurest oli veidi keerukaski laskuda argikultuuri üle arutlema. Aga tulgem selle teema juurde veel tagasi.

Konverentsijärgsed käigud viisid meid Slovaki Teaduste Akadeemia Etnoloogiainstituuti, mille raamatukogus veetsime mitmeid

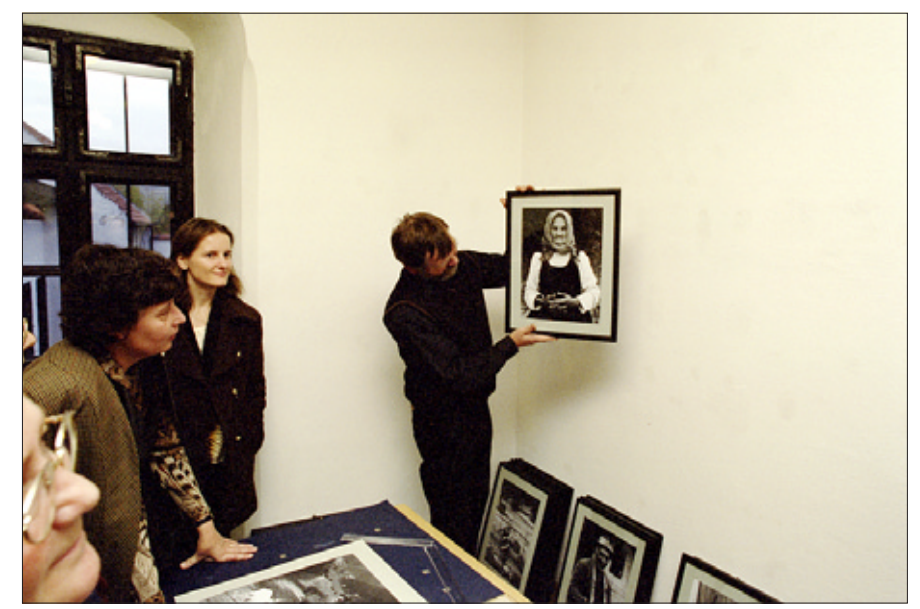

Foto 3. Ján Štrba portereteerib koduküla vanu elanikke ja nende eluolu. Slovaki tuntum fotograaf seab näitust üles. Kaadrisse on jäänud veel Gabriela Kiliánová ja Zuzana Galiová. Andres Kuperjanovi foto 2002. 


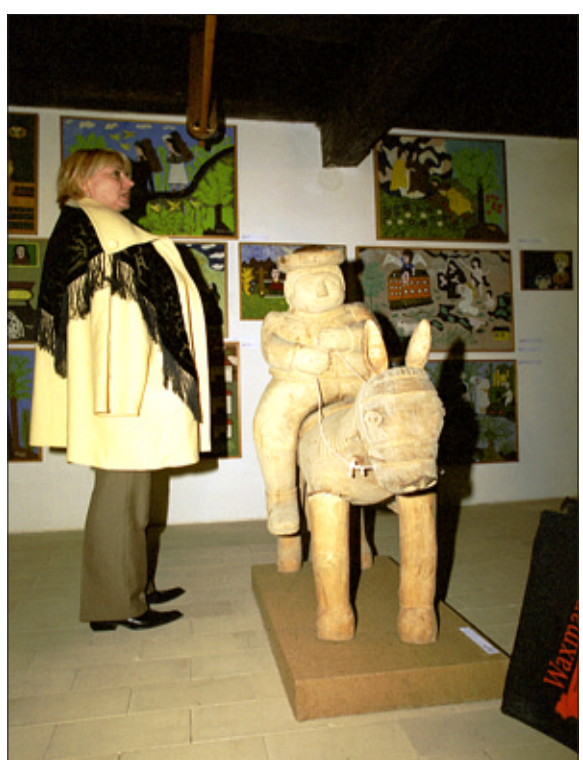

Foto 4. Zuzana Profantova tutvustab 1952. aastal Schaubmari veskis avatud naivistide muuseumi väljapanekut. Andres Kuperjanovi foto 2002. kasulikke tunde ja kus kohtasime Viera Gasparikovaga, muinasjutu-uurijaga, kelle rahvaproosa kataloogi õnnelikeks omanikeks konverentsi ajal saime. Hiljuti ilmunud nägus röövlipärimuse raamat viis mõtted vanadele ja uutele kodustele röövlitele.

Etnoloogiainstituut on mitme interdistsiplinaarse projektiga tippkeskus, mis koondab oma teemade juurde muudegi Teaduste Akadeemia asutuste uurijaid. Arhiivis, mida suvise veeuputuse aegu oli ühiste jõududega evakueeritud, leiduvad vanad käsikirjad, raamatud, kaardid, joonised ja fotod, välitööde materjalid, samuti heliarhiiv.

Viimasel aastakümnel on loobutud mitmetest varasematest uurimisparadigmadest. Instituudi praegused uurimisteemad puudutavad 20. sajandi maa- ja linnakultuuri muutusi, rahvuslikkust ja minoriteete, identiteeti ja suulist ajalugu, slovaki kultuuripärandit Kesk- ja Ida-Euroopa traditsioonide taustal jm. Abivalmis kaastöötajad on erinevas vanuses ja järelkasvu probleeme ilmsesti ei ole.

Perioodilistest väljaannetest ilmuvad eakas Slovenský národopis / Slovak Ethnology, Etnologické rozpravy, slovaki rahvaluule bibliograafia jm.

Külastame ka Komenski Ülikooli. Neljandal korrusel asuvat etnoloogia õppetooli juhatab Milan Leščák. Ôppetooli juures tegutseb muu hulgas ka maailmausunditele keskendunud usundiuurimise rühm. Ühe teemana on vaatluse all New Age. Õppetoolis uuritakse minoriteete, sh slovakkia ungarlasi ja kultuuridevahelist kommunikatsiooni: slovaki-ungari-saksa kultuurikontakte, Komarno etnilist olukorda 20. sajandil jm teemasid. Ka siin on kogenud õppejõudude ja uurijate kõrval noori, üliõpilasi on arvukalt. Slovaki etnoloogidel, 
nagu keeletadlastel ja folkloristidelgi, on olnud tihedad sidemed slaavi, eriti vene folkloristide ja Moskva koolkondadega, sh P. Bogatõrjoviga.

Slovaki suulise pärimuse, eriti rahvamuusika hämmastavat ungari-balkani münti tajume Pezinska Baba rahvuslikus stiilis külakõrtsis. Saabunud väga headele pillimeestele ja lauljatele sekundeerivad Milan Leščák ja Ivan Murín, kuid ka teised slovaki folkloristid. Peakorraldaja hea tahe viib meid veel Schaubmari veskisse, kus asub 1952. aastal asutatud naivistide muuseumgalerii täis slaaviungari tugevavärviliste maalide ja skulptuuride kuuma sõnumit (http:/www.sng.sk/sng/docsng.nsf/(w)/A01B7AD41D3B4311C1256B5 C0006F7F3). Meil veab veel sellegi võrra, et parasjagu seab samas näitust üles Ján Štrba, fotograaf, kes on aastakümneid pildistanud oma küla vanainimesi. Mustvalgetelt soojadelt humoorikatelt piltidelt vaatavad vastu vanainimese näojoonte väljendusrikkus ja kirkus. Konverentsi lõpupäeval saabuvad Palffy aiapalee juurde autokoormad kaasaegse slovaki kunstiga. Liigun harjumuspäratu värvigammaga graafika, maalide, fotode vahel. Autodest aina kantakse seinte äärde õhulist ja traagilist. Palees kohtuvad paari päeva pärast Tšehhi ja Slovaki president, see on avalöök, millega konverentsivaikus vahetab end suurejoonelisuse vastu. Sedasi sebivate inimeste ja kunsti keskel meenuvad Bratislava kesklinna humoristlikud

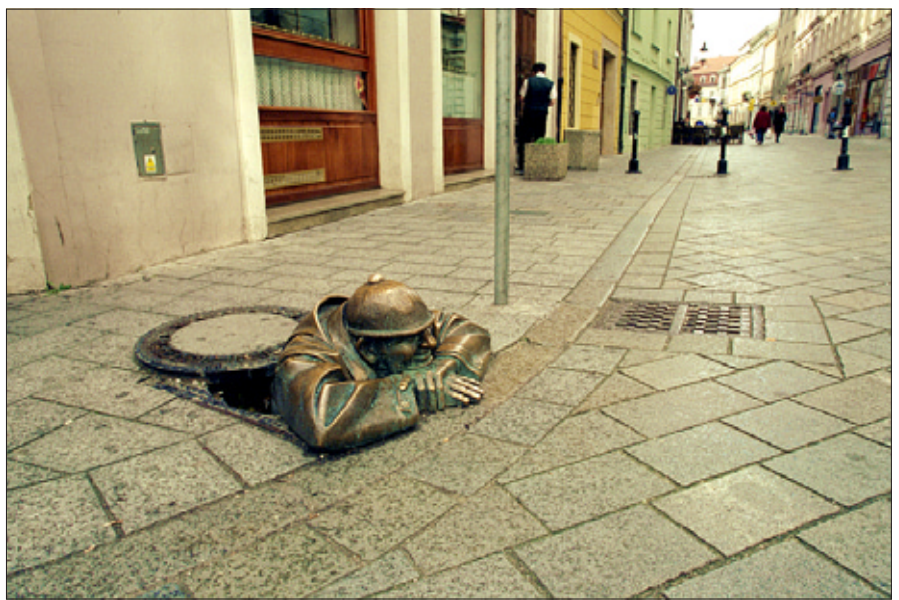

Foto 5. Bratislava vanalinna tänavail on mitmed naljakad skulptuurid. 2002. Andres Kuperjanovi foto. 
tänavaskulptuurid - piiluja, lehelugeja, nõjatuja jt. Harva on ühe konverentsi jooksul võimalik nii sügavalt ja palju kogeda ja näha ning liigagi kiiresti saabub aeg ütelda: Ela hästi, kaunis maa!

Tagasiteel jõuame Läti Rahvaluule Arhiivi konverentsi Baronsi kapp viimasele ettekandele. Vaatame kuulsat dainade kollektsiooni, mis on kolinud rahvaluule arhiivist suurde raudkappi pärisarhiivis. Vahetame kiiruudiseid Soome, Läti ja Vene kolleegidega ja - Tartusse. Jah, pikka iga folkloristikale ja folkloristidele! Kus iganes ja mis viisil nad oma materjali ka ei analüüsi. 